\title{
Genetics of Atrial Fibrillation and Possible Implications for Ischemic Stroke
}

\author{
Robin Lemmens, ${ }^{1,2,3}$ Sylvia Hermans, ${ }^{3}$ Dieter Nuyens, ${ }^{4}$ and Vincent Thijs $1,2,3$ \\ ${ }^{1}$ Department of Neurology and Laboratory for Neurobiology, Section of Experimental Neurology, School of Medicine, \\ University of Leuven, Herestraat 49, 3000 Leuven, Belgium \\ ${ }^{2}$ Vesalius Research Center (VIB), Herestraat 49, 3000 Leuven, Belgium \\ ${ }^{3}$ Department of Neurology, University Hospitals Leuven, Herestraat 49, 3000 Leuven, Belgium \\ ${ }^{4}$ Department of Cardiology, School of Medicine, University of Leuven, Herestraat 49, 3000 Leuven, Belgium
}

Correspondence should be addressed to Robin Lemmens, robin.lemmens@vib-kuleuven.be

Received 1 April 2011; Revised 25 May 2011; Accepted 31 May 2011

Academic Editor: Anna Bersano

Copyright ( 2011 Robin Lemmens et al. This is an open access article distributed under the Creative Commons Attribution License, which permits unrestricted use, distribution, and reproduction in any medium, provided the original work is properly cited.

Atrial fibrillation is the most common cardiac arrhythmia mainly caused by valvular, ischemic, hypertensive, and myopathic heart disease. Atrial fibrillation can occur in families suggesting a genetic background especially in younger subjects. Additionally recent studies have identified common genetic variants to be associated with atrial fibrillation in the general population. This cardiac arrhythmia has important public health implications because of its main complications: congestive heart failure and ischemic stroke. Since atrial fibrillation can result in ischemic stroke, one might assume that genetic determinants of this cardiac arrhythmia are also implicated in cerebrovascular disease. Ischemic stroke is a multifactorial, complex disease where multiple environmental and genetic factors interact. Whether genetic variants associated with a risk factor for ischemic stroke also increase the risk of a particular vascular endpoint still needs to be confirmed in many cases. Here we review the current knowledge on the genetic background of atrial fibrillation and the consequences for cerebrovascular disease.

\section{Introduction}

Of all cardiac arrhythmias, atrial fibrillation $(\mathrm{AF})$ is the most common, affecting approximately $1-2 \%$ of the population [1]. The prevalence is higher in men compared to women and increases with age, which is reflected by the finding that $25 \%$ of the population aged over 40 will develop $\mathrm{AF}$ [2]. Patients with AF frequently have other cardiovascular and noncardiovascular comorbidities, the most important condition being hypertension [3], which is an important risk factor for the development of $\mathrm{AF}[4]$. AF is not a benign disease as it is associated with increased rates of death, stroke, ischemic heart disease, heart failure, and peripheral thrombo-embolic events. In patients with AF, various independent factors raise the risk of stroke such as the presence of hypertension, advancing age and diabetes and the previous occurrence of a stroke or transient ischemic attack (TIA) $[5,6]$. Epidemiological studies have identified various risk factors for AF which include age, male sex, hypertension and the presence of structural heart abnormalities. However, it was suspected that the totality of the risk could not be explained exclusively by these factors, and a genetic risk component was suspected [7]. Although the vast majority of AF is sporadic and nonfamilial, familial (hereditary) forms of AF have been identified (Table 1). Also, the genetic background of AF in the general population has been studied through association studies (Table 1). Since stroke is a major complication of AF, genetic variants associated with this arrhythmia may be implicated in ischemic cerebrovascular disease. We present an overview of the current knowledge in the monogenic forms and complex genetics of AF and discuss the consequences for ischemic stroke.

\section{Pathophysiology}

Various structural cardiac abnormalities can result in a process of remodeling in the ventricles and atria. This remodeling is characterized by the proliferation of myofibroblasts 
TABLE 1: Genetics of atrial fibrillation.

\begin{tabular}{|c|c|c|c|}
\hline & Gene/Locus & Mechanism of action & Study design/Inheritance \\
\hline \multirow[t]{2}{*}{ Sodium channels } & SCNA5 [8-17] & $\begin{array}{l}\text { Cellular hyperexcitability (gain-of-function) } \\
\text { as well as prolongation of the atrial action } \\
\text { potential duration (loss-of-function) }\end{array}$ & Candidate gene/Familial and sporadic \\
\hline & SCN1B/SCN2B [18] & Decreased peak sodium current amplitude & Candidate gene/Sporadic \\
\hline \multirow{5}{*}{ Potassium channels } & KCNQ1 [19-22] & $\begin{array}{l}\text { Enhanced atrial action potential } \\
\text { repolarization }\end{array}$ & Linkage/Familial \\
\hline & KCNE2 [23] & $\begin{array}{l}\text { Enhanced atrial action potential } \\
\text { repolarization }\end{array}$ & Candidate gene/Familial \\
\hline & KCNJ2 [24] & $\begin{array}{l}\text { Enhanced atrial action potential } \\
\text { repolarization }\end{array}$ & Candidate gene/Familial \\
\hline & KCNE5 [25] & $\begin{array}{l}\text { Enhanced atrial action potential } \\
\text { repolarization }\end{array}$ & Candidate gene/Familial and sporadic \\
\hline & KCNA5 [26-28] & $\begin{array}{l}\text { Delayed atrial action potential } \\
\text { repolarization }\end{array}$ & Candidate gene/Familial and sporadic \\
\hline \multirow{8}{*}{ Other } & NPPA [29] & $\begin{array}{l}\text { Shortening of the atrial action potential } \\
\text { duration }\end{array}$ & Linkage/Familial \\
\hline & GJA5 [30-32] & Dispersion of conduction velocity & Candidate gene/Sporadic \\
\hline & $10 \mathrm{q} 22[33]$ & Unknown & Linkage/Familial \\
\hline & $6 q 14-16[34]$ & Unknown & Linkage/Familial \\
\hline & $5 p 15[35]$ & Unknown & Linkage/Familial \\
\hline & 4q25 (PITX2) [36, 37] & Unknown & Genome wide association/Sporadic \\
\hline & $16 q 22($ ZFHX3) [38] & Unknown & Genome wide association/Sporadic \\
\hline & 1q21 (KCNN3) [39] & Unknown & Genome wide association/Sporadic \\
\hline
\end{tabular}

and the development of fibrosis. Interstitial fibrosis leads to electrical uncoupling and conduction slowing, which promotes AF. If atrial fibrillation persists for several days, electrical and structural remodeling occurs promoting further maintenance of AF [40, 41]. Electrophysiologically several mechanisms have been identified which trigger and maintain the arrhythmia.

The mechanisms by which AF becomes thrombogenic are complex and have not been completely elucidated. It has become clear that the mere presence of blood stasis is not a sufficient explanation for thrombus formation. Various alterations related to AF and associated comorbidities as abnormal changes in flow, vessel wall, and blood components, probably drive a hypercoagulable state [42].

Considering the pathophysiology and taking into account the suspected genetic background in the disease it could be assumed that mutations or variants in genes of ion channels, which are of importance in atrial electrophysiology, are implicated in AF. This has been confirmed by linkage, candidate, and genome-wide genetic association studies.

\section{Monogenetic Forms of AF}

3.1. Familial AF. Studies aimed to identify the pathogenesis of AF have focused on the familial forms of the disease. In these rare familial forms different loci, as well as mutations in a range of genes have been linked to AF. Various mutations in genes encoding sodium channels (SCN5A, SCN1B, and SCN2B), potassium channels (KCNQ1, KCNE2, KCNJ2,
KCNE5, and KCNA5), natriuretic peptide (ANP) and Connexin 40 have been identified. Additionally, the culprit genes at loci on chromosome 10q22 [33], 6q14-16 [34], and 5p15 [35] have yet to be found.

3.1.1. Sodium Channel Mutations. The human cardiac sodium channel (SCN5A) is responsible for fast depolarization of cardiomyocytes and has been a therapeutic target for antiarrhythmic drugs. Initially mutations in SCN5A were identified in families with long QT syndrome [8]. Over the years, more than 200 mutations have been reported in SCN5A which are associated with variable cardiac diseases like Brugada syndrome, progressive conduction defect, sick sinus node syndrome, dilated cardiomyopathy and AF [9]. Genotype-phenotype correlations revealed that most mutations are linked to specific clinical spectrums, but that clinical overlaps exist for the same genetic defects [10]. Both Brugada syndrome and long QT syndrome can be complicated with supraventricular arrhythmias which often include AF [11]. More evidence for the role of mutations in SCN5A in the pathophysiology of AF was provided by the identification of a family with a dilated cardiomyopathy and AF carrying a mutation in SCN5A [12]. Additionally, novel mutations in the same gene were reported in familial forms of AF with and without structural cardiac disease [13-16]. It was determined that rare variants in SCN5A are present in nearly $6 \%$ of AF probands [14]. In two studies, functional analysis of the mutation showed a depolarizing shift in steady-state inactivation resulting in cellular hyperexcitability (gain of 
function) $[15,16]$. A loss of function was suggested by the study of another variant which revealed a hyperpolarizing shift in steady-state inactivation resulting in prolongation of the atrial action potential duration [13]. This delayed atrial repolarization could induce atrial torsades resulting in AF. Different mechanisms, both loss of function as well as gain of function, have been suggested in various syndromes. Furthermore, there is a wide spectrum of mutations which are associated with overlapping syndromes, suggesting environmental or other genetic factors to be of importance in determining the phenotype.

Interestingly, nonsynonymous variants were identified in other sodium channel subunits, two in SCN1B and two in SCN2B, in patients with AF which were absent in controls [18].

3.1.2. Mutations in Potassium Channel Genes. The voltagegated potassium current has a prominent role in the repolarization of the atrial action potential. Other potassium channels are of importance for the inward rectifier currents and the control of the resting potential. Multiple gain-of-function as well as loss-of-function mutations within potassium channel genes have been identified. A mutation in KCNQ1, a gene encoding the pore-forming $\alpha$ subunit of a cardiac voltagegated potassium channel, was originally documented as the causative gene for long QT syndrome [19]. A mutation in the same gene was the first identified genetic defect linked to lone $\mathrm{AF}[20]$. It was hypothesized that the pathogenic mechanism consisted of a gain of function by increasing the repolarizing current and shortening of the atrial action potential duration [20]. Various other gain of function mutations have subsequently been identified in isolated families in KCNQ1 [21, 22] as well as in other potassium channel genes, including KCNE2 [23], KCNJ2 [24], and KCNE5 [25]. Additionally, in another potassium channel gene, KCNA5, loss-of-function mutations were identified in a small number of families [2628]. Functional analysis of this mutation revealed delayed action potential repolarization and prolongation of the atrial action potential duration (a mechanism similar as reported for a SCN5A mutation [13]).

3.1.3. Atrial Natriuretic Peptide (ANP). In a linkage study of a family with autosomal dominant $\mathrm{AF}$, a mutation in the natriuretic peptide precursor gene (NPPA) was identified [29]. The mutation produced the loss of a stop codon resulting in the expression of a longer peptide. The concentration of the mutant peptide was 5 to 10 times increased in the plasma compared to the wild type suggesting a longer halflife potentially due to resistance to degradation. In an isolated whole-heart model, the mutant peptide caused shortening of the atrial action potential duration (analogous to what is reported for most of the potassium channel mutations).

Another possible pathophysiological mechanism of the mutation might involve structural changes resulting in atrial fibrosis due to exposure to high concentrations of (mutant) ANP [29].

3.1.4. Connexin 40. The initially discovered genes found in familial AF were a rare cause of lone AF $[43,44]$. Therefore, additional research focused at other pathogenic pathways. Attractive genes included the connexins, which are proteins that form gap junctions and provide low-resistance electrical coupling between cells. Especially the gene GJA5, coding for connexin 40, gained interest since it is expressed at high levels in atria. Furthermore, conduction disturbances have been identified in GJA5-knockout mice resulting in atrial vulnerability and possibly arrhythmogenesis [45]. Sequencing of genomic DNA from cardiac tissue of 15 patients with idiopathic AF indeed identified four missense mutations, of which three were thought to be of somatic origin. The mutated protein was heterogeneously distributed in atrial tissue and a loss-of-function was hypothesized [30], resulting in exaggerated dispersion of conduction velocity predisposing to and sustaining AF. Moreover, a similar genetic mosaicism in atrial tissue linked to $\mathrm{AF}$ was recently reported in one patient with lone AF for the GJA1 gene, coding for the connexin 43 protein [46].

3.2. AF in Other Inherited Disorders. In several genetic cardiac syndromes, both with and without structural abnormalities, AF has been described as part of the clinical spectrum. Short and long QT and Brugada are associated with supraventricular arrhythmias, which often comprise AF. Various other inherited cardiac disorders are characterized by the occurrence of AF as hypertrophic cardiomyopathy, ventricular preexcitation and abnormal left ventricle hypertrophy linked to mutations in the PRKAG gene [11].

\section{Complex Genetics of AF}

Whereas genetic studies in familial forms of AF have implicated various genes in a limited number of cases, epidemiologic studies in the general population have documented a genetic component to AF in sporadic AF. Parental AF was shown to increase the risk for future $\mathrm{AF}$, an association which was stronger at younger age and for lone AF [47-49]. Candidate gene studies in sporadic AF investigating common variants in the genome suggested a role for polymorphisms in regions implicated in familial AF [17, 31, $32,50-54$ ] as well as others [55-63]. An association for a common polymorphism in SCN5A with paroxysmal AF was reported, although replication of this finding is lacking [17]. Common variants in GJA5 have also been shown to associate with atrial fibrillation in sporadic $\operatorname{AF}[31,32]$. The sample sizes in most of these studies were relatively small and large replication studies were lacking. Meta-analyses of studies determining the role of polymorphisms in the renin-angiotensin system-related gene with AF suggested a possible association between angiotensin converting enzyme (ACE) insertion/deletion and AF risk [64, 65]. However a large replication study recently failed to replicate any of the reported associated polymorphisms at this locus or any other locus [66].

Since most of the candidate gene studies have not been successful, results of genome-wide studies were anxiously awaited as for many complex diseases [67]. Two sequence variants on chromosome $4 \mathrm{q} 25$ were identified in the first reported genome-wide association study in AF [36]. These 
variants have been replicated extensively. Two additional variants in this region were found, and the possibility of multiple susceptibility signals at this locus was hypothesized [37]. The reported variants were adjacent to the PITX2 gene, a transcriptional factor critical for determining leftright asymmetry and for the differentiation of the left atrium [68]. Increasing the initial sample size revealed an additional sequence variant in the ZFHX3 gene in chromosome 16q22 as a risk factor for AF [38]. A third locus was identified on chromosome 1q21 in KCNN3, a gene which encodes a potassium channel protein involved in atrial repolarization [39]. The variant rs 2200733 on $4 \mathrm{q} 25$ remained the variant with the largest effect size, with an estimated odds ratio in the range of 1.80 (95\% CI 1.50-2.15) [37]/1.90 (95\% CI 1.602.26) [69]. Increasing sample sizes in genetic association studies will potentially reveal yet unknown loci implicated in AF.

\section{Implications for Ischemic Stroke}

Ischemic stroke can be categorized into several etiological subgroups: cardioembolic stroke, large-artery atherosclerosis, small-vessel disease, undetermined (cryptogenic, multiple causes, or incomplete evaluation), or other causes [70]. Approximately $20 \%$ of ischemic strokes are due to cardiac embolism mainly caused by atrial fibrillation (AF), which can be either paroxysmal or persistent with both variants resulting in a similar stroke risk [71]. It is thought that some strokes of undetermined origin are actually due to undiagnosed paroxysmal AF [72]. Since stroke can be a clinical complication of sporadic AF, the risk of stroke is also increased in familial cases of AF. Other inherited cardiac disorders characterized by AF can also present with stroke. In hypertrophic cardiomyopathies, for instance, the stroke risk is increased and this is directly linked to the occurrence of AF [73].

Stroke is considered a complex disease where a genetic component in the etiology is suspected. Candidate gene studies in stroke have resulted in largely disappointing findings [74]. Findings of a large genome wide association study in stroke could not be replicated $[75,76]$. An association was reported in a genome-wide association study in stroke for the initially reported risk variant rs2200733 on $4 \mathrm{q} 25$ with AF, OR 1.26 (95\% CI 1.17-1.35) [77]. This association was most pronounced in the cardioembolic subgroup of stroke. We replicated these findings and identified this variant exclusively in cardioembolic stroke, suggesting that this variant is indirectly linked to stroke through AF [78]. The effect size of this genetic variant in cardioembolic stroke is somewhat smaller than what has been reported for AF, OR: 1.52 (95\% CI 1.35-1.71) [77] and 1.47 (95\% CI 1.28-1.71) [78]. This could be due the fact that in most selected controls, stroke-free status was ensured while AF-free status was not determined. Additionally, not all patients with cardioembolic stroke are diagnosed with AF (in our replication study this percentage was 61\%). Similar findings were obtained for the variant on $16 \mathrm{q} 22$ which also confers risk for primarily cardioembolic stroke [38].

\subsection{Influence of Cryptogenic Stroke?}

The initial report on the association of the $4 q 25$ locus with stroke stated that in subgroup analysis, the association of the $4 \mathrm{q} 25$ locus with stroke remained after all patients who suffered from cardioembolic stroke were excluded [77]. This study included five study populations totaling 29474 controls and 6222 patients. Our replication study was performed in six different populations with 3750 controls and 4199 patients. All studies included hospital-based populations (apart from the controls in one cohort in the discovery study). Phenotyping was performed according to similar protocols. Potentially the lack of replication after excluding stroke of cardioembolic embolism could be due to the somewhat smaller sample size. Additionally the findings of the initial report after excluding cardioembolic stroke might be caused by phenotypic misclassification or ascertainment bias: patients classified as having a stroke of undetermined etiology could in reality have a stroke of (unidentified) cardioembolic etiology because AF was not detected during the hospital stay or because the investigation into cardioembolic sources was not extensively performed. In our replication study, the variants on 4 q25 lacked association with true cryptogenic stroke, arguing against a large percentage of these patients suffering from unrevealed cardioembolic stroke. This analysis was not performed in the initial report. Additionally in our replication study, we identified an interaction between cardioembolic stroke and the risk variant on 4q25 supporting the hypothesis that the relation is mainly caused by this subtype of stroke.

Since the genotyping of these variants has become commercially available, it might be tempting to offer patients with stroke of cryptogenic etiology genetic testing for AF inducing variants. Patients carrying the risk variant (of which the allele frequency is estimated to be $10 \%$ in the general population) could, for example, be more extensively studied for paroxysmal AF. Our results do not provide evidence for performing such individually based genotyping since no association was identified in cryptogenic stroke patients.

5.2. Stroke as a Phenotype or Stroke as a Conglomerate of Phenotypes. The findings from these genetic association studies underline that genetic risk factors may predispose to a particular subgroup of stroke. The fact that a variant on chromosome 9 associated with myocardial infarction and coronary artery disease also is associated with stroke due to large-vessel atherosclerotic disease emphasizes this assumption [79, 80]. Stroke is a heterogeneous disorder, and this heterogeneity might be the reason for the disappointing results in genetic association studies in the stroke field so far. It can be assumed that genetic risk factors are implicated only in subgroups of stroke, and, therefore, analyzing each subgroup is of importance. In order to obtain convincing results from GWAS, accurate stroke phenotyping and large sample sizes for each stroke subtype will be required.

5.3. Stroke as a Vascular Endpoint. Stroke can be regarded as the clinical outcome of other underlying diseases; this seems 
applicable not only to AF and cardioembolic stroke but also for stroke due to large-vessel disease and atherosclerosis. One could argue that data of various disease traits that share underlying pathogenic mechanisms could be combined in meta-analyses of genome-wide association studies to increase power. Moreover, it could be considered to analyze cases of underlying diseases together with cases of the associated clinical outcome. For instance, data obtained in genome-wide association studies in AF can be merged with the data of all cardioembolic stroke cases. Similarly, coronary artery disease, peripheral artery disease and stroke due to large-vessel disease could be jointly examined. This does not entirely exclude the possibility that genetic variants will be identified for ischemic stroke in general. However, the other approaches (combining vascular diseases or merging risk factors and their outcomes) could increase power and could eventually lead to the identification of genetic polymorphisms conferring risk for (subtypes of) stroke. Although typically this will lead to findings of small effect size, this does not imply that the biological relevance cannot be greater than the genetic effect.

In complex diseases (as stroke), it is assumed that various environmental factors together with genetic variants can result in a certain disease phenotype. Interfering with several (but not necessarily all) of these factors might already result in reducing risk and, therefore, less clinical outcomes in the general population. Identifying the pathophysiological meaning of a genetic variant associated with AF could potentially lead to new therapeutic targets in AF and indirectly lead to a reduction in cardioembolic stroke.

\section{References}

[1] A. S. Go, E. M. Hylek, K. A. Phillips et al., "Prevalence of diagnosed atrial fibrillation in adults: national implications for rhythm management and stroke prevention: the anticoagulation and risk factors in atrial fibrillation (ATRIA) study," Journal of the American Medical Association, vol. 285, no. 18, pp. 2370-2375, 2001.

[2] D. M. Lloyd-Jones, T. J. Wang, E. P. Leip et al., "Lifetime risk for development of atrial fibrillation: the framingham heart study," Circulation, vol. 110, no. 9, pp. 1042-1046, 2004.

[3] M. Nabauer, A. Gerth, T. Limbourg et al., "The Registry of the German Competence NETwork on Atrial Fibrillation: patient characteristics and initial management," Europace, vol. 11, no. 4, pp. 423-434, 2009.

[4] S. Stewart, C. L. Hart, D. J. Hole, and J. J. V. McMurray, "Population prevalence, incidence, and predictors of atrial fibrillation in the Renfrew/Paisley study," Heart, vol. 86, no. 5, pp. 516-521, 2001.

[5] R. G. Hart, L. A. Pearce, G. W. Albers et al., "Independent predictors of stroke in patients with atrial fibrillation: a systematic review," Neurology, vol. 69, no. 6, pp. 546-554, 2007.

[6] J. B. Olesen, G. Y. Lip, M. L. Hansen et al., "Validation of risk stratification schemes for predicting stroke and thromboembolism in patients with atrial fibrillation: nationwide cohort study," British Medical Journal, vol. 34, article d124, 2011.

[7] E. J. Benjamin, D. Levy, S. M. Vaziri, R. B. D’Agostino, A. J. Belanger, and P. A. Wolf, "Independent risk factors for atrial fibrillation in a population-based cohort. The Framingham
Heart Study," Journal of the American Medical Association, vol. 271, no. 11, pp. 840-844, 1994.

[8] Q. Wang, J. Shen, I. Splawski et al., "SCN5A mutations associated with an inherited cardiac arrhythmia, long QT syndrome," Cell, vol. 80, no. 5, pp. 805-811, 1995.

[9] Y. Ruan, N. Liu, and S. G. Priori, "Sodium channel mutations and arrhythmias," Nature Reviews Cardiology, vol. 6, no. 5, pp. 337-348, 2009.

[10] C. Napolitano, I. Rivolta, and S. G. Priori, "Cardiac sodium channel diseases," Clinical Chemistry and Laboratory Medicine, vol. 41, no. 4, pp. 439-444, 2003.

[11] P. Kirchhof, J. Bax, C. Blomstrom-Lundquist et al., "Early and comprehensive management of atrial fibrillation: executive summary of the proceedings from the 2nd AFNET-EHRA consensus conference 'research perspectives in AF', European Heart Journal, vol. 30, no. 24, pp. 2969-2977, 2009.

[12] T. M. Olson, V. V. Michels, J. D. Ballew et al., "Sodium channel mutations and susceptibility to heart failure and atrial fibrillation," Journal of the American Medical Association, vol. 293, no. 4, pp. 447-454, 2005.

[13] P. T. Ellinor, E. G. Nam, M. A. Shea, D. J. Milan, J. N. Ruskin, and C. A. MacRae, "Cardiac sodium channel mutation in atrial fibrillation," Heart Rhythm, vol. 5, no. 1, pp. 99-105, 2008.

[14] D. Darbar, P. J. Kannankeril, B. S. Donahue et al., "Cardiac sodium channel (SCN5A) variants associated with atrial fibrillation," Circulation, vol. 117, no. 15, pp. 1927-1935, 2008.

[15] T. Makiyama, M. Akao, S. Shizuta et al., "A novel SCN5A gainof-function mutation M1875T associated with familial atrial fibrillation," Journal of the American College of Cardiology, vol. 52, no. 16, pp. 1326-1334, 2008.

[16] Q. Li, H. Huang, G. Liu et al., "Gain-of-function mutation of Nav1.5 in atrial fibrillation enhances cellular excitability and lowers the threshold for action potential firing," Biochemical and Biophysical Research Communications, vol. 380, no. 1, pp. 132-137, 2009.

[17] L. Y. Chen, J. D. Ballew, K. J. Herron, R. J. Rodeheffer, and T. M. Olson, "A common polymorphism in SCN5A is associated with lone atrial fibrillation," Clinical Pharmacology and Therapeutics, vol. 81, no. 1, pp. 35-41, 2007.

[18] H. Watanabe, D. Darbar, D. W. Kaiser et al., "Mutations in Sodium Channel $\beta 1$ - and $\beta 2$-Subunits Associated With Atrial Fibrillation," Circulation, vol. 2, no. 3, pp. 268-275, 2009.

[19] Q. Wang, M. E. Curran, I. Splawski et al., "Positional cloning of a novel potassium channel gene: KVLQT1 mutations cause cardiac arrhythmias," Nature Genetics, vol. 12, no. 1, pp. 1723, 1996.

[20] Y. H. Chen, S. J. Xu, S. Bendahhou et al., "KCNQ1 gainof-function mutation in familial atrial fibrillation," Science, vol. 299, no. 5604, pp. 251-254, 2003.

[21] S. Das, S. Makino, Y. F. Melman et al., "Mutation in the S3 segment of KCNQ1 results in familial lone atrial fibrillation," Heart Rhythm, vol. 6, no. 8, pp. 1146-1153, 2009.

[22] A. Lundby, L. S. Ravn, J. H. Svendsen, S. P. Olesen, and N. Schmitt, "KCNQ1 mutation Q147R is associated with atrial fibrillation and prolonged QT interval," Heart Rhythm, vol. 4, no. 12, pp. 1532-1541, 2007.

[23] Y. Yang, M. Xia, Q. Jin et al., "Identification of a KCNE2 gain-of-function mutation in patients with familial atrial fibrillation," American Journal of Human Genetics, vol. 75, no. 5, pp. 899-905, 2004.

[24] M. Xia, Q. Jin, S. Bendahhou et al., "A Kir2.1 gain-of-function mutation underlies familial atrial fibrillation," Biochemical and Biophysical Research Communications, vol. 332, no. 4, pp. 1012-1019, 2005. 
[25] L. S. Ravn, Y. Aizawa, G. D. Pollevick et al., "Gain of function in IKs secondary to a mutation in KCNE5 associated with atrial fibrillation," Heart Rhythm, vol. 5, no. 3, pp. 427-435, 2008.

[26] T. M. Olson, A. E. Alekseev, X. K. Liu et al., "Kv1.5 channelopathy due to KCNA5 loss-of-function mutation causes human atrial fibrillation," Human Molecular Genetics, vol. 15, no. 14, pp. 2185-2191, 2006.

[27] Y. Yang, J. Li, X. Lin et al., "Novel KCNA5 loss-of-function mutations responsible for atrial fibrillation," Journal of Human Genetics, vol. 54, no. 5, pp. 277-283, 2009.

[28] T. Yang, P. Yang, D. M. Roden, and D. Darbar, "Novel KCNA5 mutation implicates tyrosine kinase signaling in human atrial fibrillation," Heart Rhythm, vol. 7, no. 9, pp. 1246-1252, 2010.

[29] D. M. Hodgson-Zingman, M. L. Karst, L. V. Zingman et al., "Atrial natriuretic peptide frameshift mutation in familial atrial fibrillation," The New England Journal of Medicine, vol. 359, no. 2, pp. 158-165, 2008.

[30] M. H. Gollob, D. L. Jones, A. D. Krahn et al., "Somatic mutations in the connexin 40 gene (GJA5) in atrial fibrillation," The New England Journal of Medicine, vol. 354, no. 25, pp. 26772688, 2006.

[31] M. Firouzi, H. Ramanna, B. Kok et al., "Association of human connexin40 gene polymorphisms with atrial vulnerability as a risk factor for idiopathic atrial fibrillation," Circulation Research, vol. 95, no. 4, pp. e29-e33, 2004.

[32] J. M. Juang, Y. R. Chern, C. T. Tsai et al., "The association of human connexin 40 genetic polymorphisms with atrial fibrillation," International Journal of Cardiology, vol. 116, no. 1, pp. 107-112, 2007.

[33] R. Brugada, T. Tapscott, G. Z. Czernuszewicz et al., "Identification of a genetic locus for familial atrial fibrillation," The New England Journal of Medicine, vol. 336, no. 13, pp. 905911, 1997.

[34] P. T. Ellinor, J. T. Shin, R. K. Moore, D. M. Yoerger, and C. A. MacRae, "Locus for atrial fibrillation maps to chromosome 6q14-16," Circulation, vol. 107, no. 23, pp. 2880-2883, 2003.

[35] D. Darbar, A. Hardy, J. L. Haines, and D. M. Roden, "Prolonged signal-averaged P-wave duration as an intermediate phenotype for familial atrial fibrillation," Journal of the American College of Cardiology, vol. 51, no. 11, pp. 1083-1089, 2008.

[36] D. F. Gudbjartsson, D. O. Arnar, A. Helgadottir et al., "Variants conferring risk of atrial fibrillation on chromosome 4q25," Nature, vol. 448, no. 7151, pp. 353-357, 2007.

[37] S. A. Lubitz et al., "Independent susceptibility markers for atrial fibrillation on chromosome 4q25," Circulation, vol. 122, no. 10, pp. 976-984, 2010.

[38] D. F. Gudbjartsson, H. Holm, S. Gretarsdottir et al., "A sequence variant in ZFHX3 on 16q22 associates with a trial fibrillation and ischemic stroke," Nature Genetics, vol. 41, no. 8, pp. 876-878, 2009.

[39] P. T. Ellinor, K. L. Lunetta, N. L. Glazer et al., "Common variants in KCNN3 are associated with lone atrial fibrillation," Nature Genetics, vol. 42, no. 3, pp. 240-244, 2010.

[40] A. J. Camm et al., "Guidelines for the management of atrial fibrillation: the Task Force for the Management of Atrial Fibrillation of the European Society of Cardiology (ESC)," European Heart Journal, vol. 31, no. 19, pp. 2369-2429, 2010.

[41] M. C. E. F. Wijffels, C. J. H. J. Kirchhof, R. Dorland, and M. A. Allessie, "Atrial fibrillation begets atrial fibrillation: a study in awake chronically instrumented goats," Circulation, vol. 92, no. 7, pp. 1954-1968, 1995.
[42] T. Watson, E. Shantsila, and G. Y. Lip, "Mechanisms of thrombogenesis in atrial fibrillation: virchow's triad revisited," The Lancet, vol. 373, no. 9658, pp. 155-166, 2009.

[43] P. T. Ellinor, R. K. Moore, K. K. Patton, J. N. Ruskin, M. R. Pollak, and C. A. MacRae, "Mutations in the long QT gene, KCMQ1, are an uncommon cause of atrial fibrillation," Heart, vol. 90, no. 12, pp. 1487-1488, 2004.

[44] P. T. Ellinor, V. I. Petrov-Kondratov, E. Zakharova, E. G. Nam, and C. A. MacRae, "Potassium channel gene mutations rarely cause atrial fibrillation," BMC Medical Genetics, vol. 7, article 70, 2006.

[45] A. Hagendorff, B. Schumacher, S. Kirchhoff, B. Lüderitz, and K. Willecke, "Conduction disturbances and increased atrial vulnerability in connexin40-deficient mice analyzed by transesophageal stimulation," Circulation, vol. 99, no. 11, pp. 1508-1515, 1999.

[46] I. L. Thibodeau, J. Xu, Q. Li et al., "Paradigm of genetic mosaicism and lone atrial fibrillation: physiological characterization of a connexin 43-deletion mutant identified from atrial tissue," Circulation, vol. 122, no. 3, pp. 236-244, 2010.

[47] C. S. Fox, H. Parise, R. B. D'Agostino et al., "Parental atrial fibrillation as a risk factor for atrial fibrillation in offspring," Journal of the American Medical Association, vol. 291, no. 23, pp. 2851-2855, 2004.

[48] P. T. Ellinor, D. M. Yoerger, J. N. Ruskin, and C. A. MacRae, "Familial aggregation in lone atrial fibrillation," Human Genetics, vol. 118, no. 2, pp. 179-184, 2005.

[49] I. E. Christophersen, L. S. Ravn, E. Budtz-Joergensen et al., "Familial aggregation of atrial fibrillation: a study in danish twins," Circulation, vol. 2, no. 4, pp. 378-383, 2009.

[50] Z. Zeng, C. Tan, S. Teng et al., "The single nucleotide polymorphisms of IKs potassium channel genes and their association with atrial fibrillation in a Chinese population," Cardiology, vol. 108, no. 2, pp. 97-103, 2007.

[51] C. Fatini, E. Sticchi, M. Genuardi et al., "Analysis of minK and eNOS genes as candidate loci for predisposition to nonvalvular atrial fibrillation," European Heart Journal, vol. 27, no. 14, pp. 1712-1718, 2006.

[52] L. P. Lai, M. J. Su, H. M. Yeh et al., "Association of the human minK gene $38 \mathrm{G}$ allele with atrial fibrillation: evidence of possible genetic control on the pathogenesis of atrial fibrillation," American Heart Journal, vol. 144, no. 3, pp. 485490, 2002.

[53] A. Prystupa, G. Dzida, W. Myśliński, G. Małaj, and T. Lorenc, "MinK gene polymorphism in the pathogenesis of lone atrial fibrillation," Kardiologia Polska, vol. 64, no. 11, pp. 1205-1211, 2006.

[54] L. S. Ravn, J. Hofman-Bang, U. Dixen et al., "Relation of 97T polymorphism in KCNE5 to risk of atrial fibrillation," American Journal of Cardiology, vol. 96, no. 3, pp. 405-407, 2005.

[55] K. Kato, M. Oguri, T. Hibino et al., "Genetic factors for lone atrial fibrillation," International Journal of Molecular Medicine, vol. 19, no. 6, pp. 933-939, 2007.

[56] C. T. Tsai, L. P. Lai, J. L. Lin et al., "Renin-angiotensin system gene polymorphisms and atrial fibrillation," Circulation, vol. 109, no. 13, pp. 1640-1646, 2004.

[57] M. Gaudino, F. Andreotti, R. Zamparelli et al., "The -174G/C interleukin-6 polymorphism influences postoperative interleukin- 6 levels and postoperative atrial fibrillation. Is atrial fibrillation an inflammatory complication?" Circulation, vol. 108, no. 10, supplement 1, pp. II195-II199, 2003. 
[58] D. Poli, E. Antonucci, E. Cecchi et al., "Thrombophilic mutations in high-risk atrial fibrillation patients: high prevalence of prothrombin gene G20210A polymorphism and lack of correlation with thromboembolism," Thrombosis and Haemostasis, vol. 90, no. 6, pp. 1158-1162, 2003.

[59] M. T. Nyberg, B. Stoevring, E. R. Behr, L. S. Ravn, W. J. McKenna, and M. Christiansen, "The variation of the sarcolipin gene (SLN) in atrial fibrillation, long QT syndrome and sudden arrhythmic death syndrome," Clinica Chimica Acta, vol. 375, no. 1-2, pp. 87-91, 2007.

[60] J. Schreieck, S. Dostal, N. Von Beckerath et al., "C825T polymorphism of the G-protein $\beta 3$ subunit gene and atrial fibrillation: association of the TT genotype with a reduced risk for atrial fibrillation," American Heart Journal, vol. 148, no. 3, pp. 545-550, 2004.

[61] F. W. Asselbergs, J. H. Moore, M. P. van den Berg et al., "A role for CETP TaqIB polymorphism in determining susceptibility to atrial fibrillation: a nested case control study," BMC Medical Genetics, vol. 7, article 39, 2006.

[62] M. Bedi, D. McNamara, B. London, and D. Schwartzman, "Genetic susceptibility to atrial fibrillation in patients with congestive heart failure," Heart Rhythm, vol. 3, no. 7, pp. 808$812,2006$.

[63] M. F. Sinner, A. Pfeufer, M. Akyol et al., "The non-synonymous coding IKr-channel variant $\mathrm{KCNH} 2-\mathrm{K} 897 \mathrm{~T}$ is associated with atrial fibrillation: results from a systematic candidate gene-based analysis of KCNH2 (HERG)," European Heart Journal, vol. 29, no. 7, pp. 907-914, 2008.

[64] P. Xiao, Z. Ling, K. Woo et al., "Renin-angiotensin systemrelated gene polymorphisms are associated with risk of atrial fibrillation," American Heart Journal, vol. 160, no. 3, pp. 496$505,2010$.

[65] T. Liu, P. Korantzopoulos, G. Xu et al., "Association between angiotensin-converting enzyme insertion/deletion gene polymorphism and atrial fibrillation: a meta-analysis," Europace, vol. 13, no. 3, pp. 346-354, 2011.

[66] M. F. Sinner, S. A. Lubitz, A. Pfeufer et al., "Lack of replication in polymorphisms reported to be associated with atrial fibrillation," Heart Rhythm, vol. 8, no. 3, pp. 403-409, 2011.

[67] T. A. Manolio, F. S. Collins, N. J. Cox et al., "Finding the missing heritability of complex diseases," Nature, vol. 461, no. 7265, pp. 747-753, 2009.

[68] M. T. M. Mommersteeg, N. A. Brown, O. W. J. Prall et al., "Pitx2c and Nkx2-5 are required for the formation and identity of the pulmonary myocardium," Circulation Research, vol. 101, no. 9, pp. 902-909, 2007.

[69] S. Kääb, D. Darbar, C. Van Noord et al., "Large scale replication and meta-analysis of variants on chromosome 4q25 associated with atrial fibrillation," European Heart Journal, vol. 30, no. 7, pp. 813-819, 2009.

[70] H. P. Adams Jr., B. H. Bendixen, L. J. Kappelle et al., "Classification of subtype of acute ischemic stroke: definitions for use in a multicenter clinical trial," Stroke, vol. 24, no. 1, pp. 35-41, 1993.

[71] L. Friberg, N. Hammar, and M. Rosenqvist, "Digoxin in atrial fibrillation: report from the Stockholm Cohort study of Atrial Fibrillation (SCAF)," Heart, vol. 96, no. 4, pp. 275-280, 2010.

[72] P. Kirchhof, A. Auricchio, J. Bax et al., "Outcome parameters for trials in atrial fibrillation: executive summary," European Heart Journal, vol. 28, no. 22, pp. 2803-2817, 2007.

[73] B. J. Maron, I. Olivotto, P. Bellone et al., "Clinical profile of stroke in 900 patients with hypertrophic cardiomyopathy," Journal of the American College of Cardiology, vol. 39, no. 2, pp. 301-307, 2002.
[74] M. Dichgans and H. S. Markus, "Genetic association studies in stroke: methodological issues and proposed standard criteria," Stroke, vol. 36, no. 9, pp. 2027-2031, 2005.

[75] M. A. Ikram, S. Seshadri, J. C. Bis et al., "Genomewide association studies of stroke," The New England Journal of Medicine, vol. 360, no. 17, pp. 1718-1728, 2009.

[76] J. Rosand, J. F. Meschia, and A. B. Singleton, "Failure to validate association between $12 \mathrm{p} 13$ variants and ischemic stroke," The New England Journal of Medicine, vol. 362, no. 16, pp. 1547-1550, 2010.

[77] S. Gretarsdottir, G. Thorleifsson, A. Manolescu et al., "Risk variants for atrial fibrillation on chromosome 4q25 associate with ischemic stroke," Annals of Neurology, vol. 64, no. 4, pp. 402-409, 2008.

[78] R. Lemmens, I. Buysschaert, V. Geelen et al., "The association of the $4 \mathrm{q} 25$ susceptibility variant for atrial fibrillation with stroke is limited to stroke of cardioembolic etiology," Stroke, vol. 41, no. 9, pp. 1850-1857, 2010.

[79] A. Gschwendtner, S. Bevan, J. W. Cole et al., "Sequence variants on chromosome 9p21.3 confer risk for atherosclerotic stroke," Annals of Neurology, vol. 65, no. 5, pp. 531-539, 2009.

[80] C. D. Anderson, A. Biffi, N. S. Rost, L. Cortellini, K. L. Furie, and J. Rosand, "Chromosome 9p21 in ischemic stroke: population structure and meta-analysis," Stroke, vol. 41, no. 6, pp. 1123-1131, 2010. 


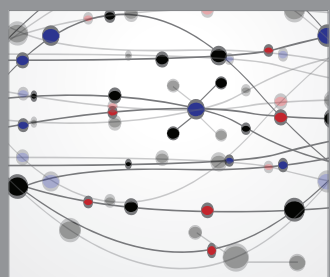

The Scientific World Journal
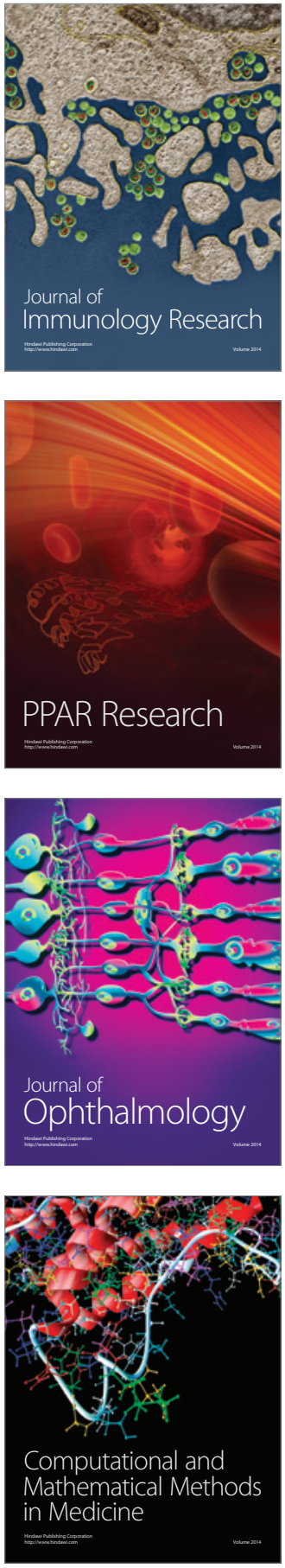

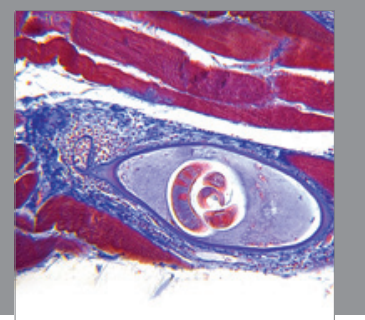

Gastroenterology

Research and Practice
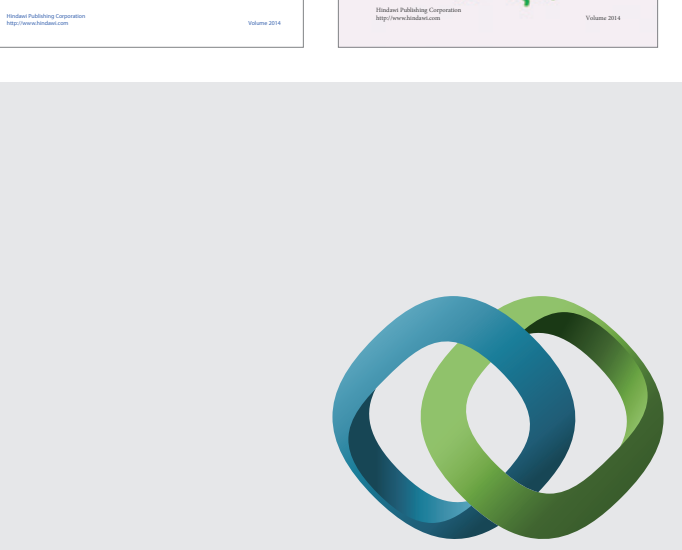

\section{Hindawi}

Submit your manuscripts at

http://www.hindawi.com
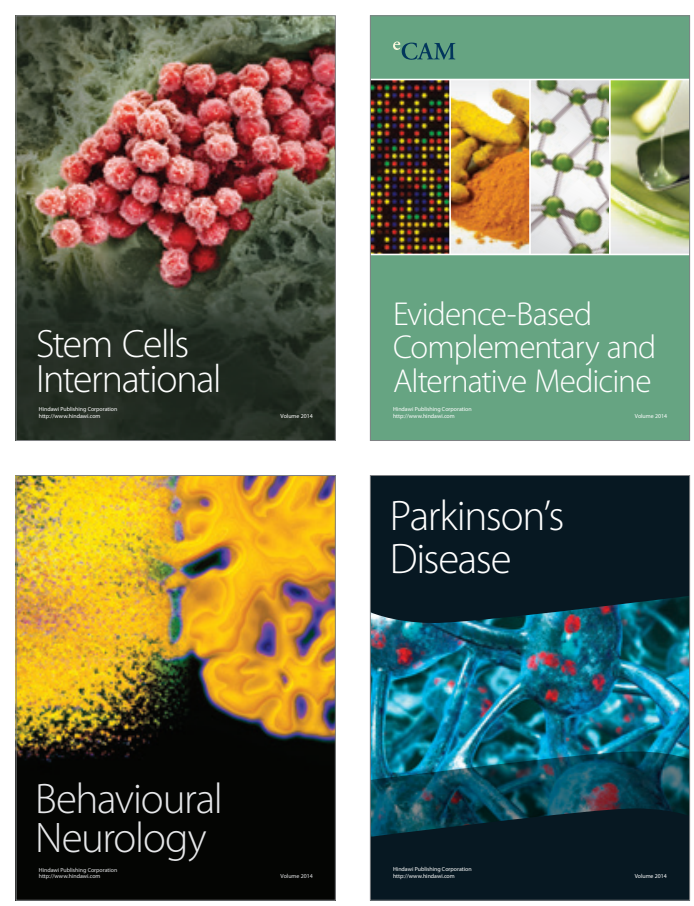

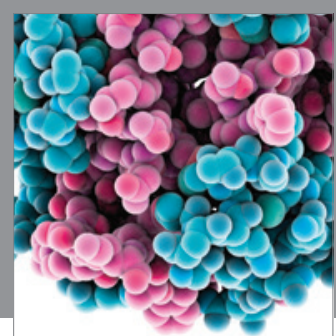

Journal of
Diabetes Research

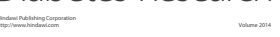

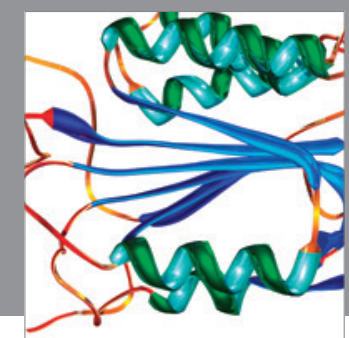

Disease Markers
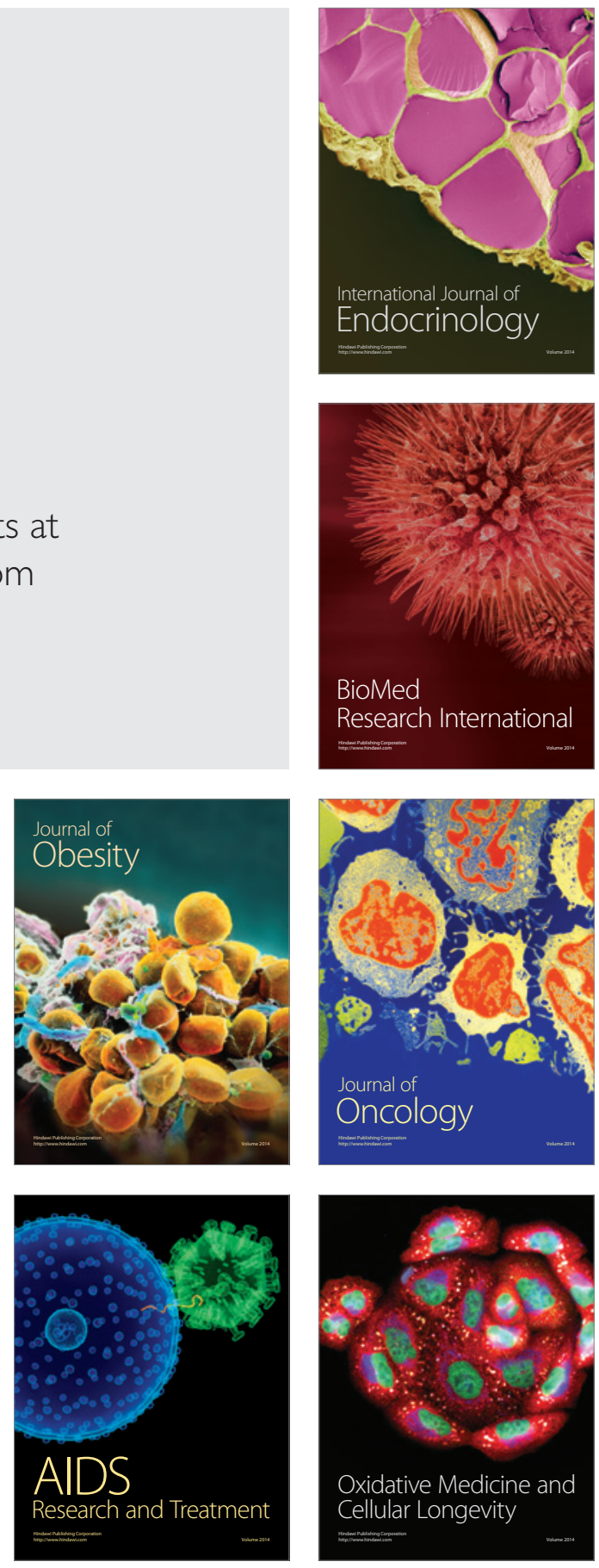